\title{
Will Schools Ever Open Up on the Growing Substance Problem?
}

\section{Nicholas Johnson*}

Intensive Outpatient Director, New Dawn Treatment Centers in Sacramento, California, USA

Keywords: Risk factors; Infants; Maternal factors; Psychiatry disorders

When I was in high school we had a program called 'Every 7 Minutes.' Every 7 minutes a class mate would be asked to leave campus for the day. It was to signify that every 7 minutes a person dies as a result of drunk driving. A car was brought in that was totaled as a result of drunk driving. Towards the end of school the campus was desolate. It was as if the campus turned into an old west town at high noon. Schools seem to be very comfortable discussing the dangers of drunk driving but what about those that don't drink? What about the ones that still drives under the influence of prescription drugs, heroin, Methamphetamine? Are schools ready to finally admit that this, too, is a big problem with students?

It seems that every couple of weeks I read an article about a student who has overdosed. It seems that it is mostly heroin which, as it has been said numerous times in other articles and research, is a growing problem with the student population. In the article some school official always says that there school is a "safe place" for students. This is almost never stated if a student dies as a result of drinking and driving. The safety of a school's campus is not considered. It is time for school districts to acknowledge that there is an ever growing problem with substances other than drinking and driving without having to worry about their school being viewed as "safe."

Please do not get me wrong. I think drinking and driving as a youth is a terrible thing and talking about it can be a great intervention, but driving under the influence of other substances is just as dangerous. In school it was talked about if you were going to drink that you should designate a driver or call your parents. With the stigma attached to drug use it seems that by mentioning drugs in the same sentence would be an act of condoning the behavior. Are we condoning drinking for our youth? No. We are simply saying that if you were to drink that there are things that can be done to ensure your safety.

Could this harm reduction rhetoric also be applied to using drugs? I think so. With the usage of drugs other than alcohol becoming more and more prevalent I think it is time to do so. Admitting that there are drugs in the schools needs to stop being associated with how safe the school is. Bringing awareness to the faculty as well as the parents could be beneficial in multiple ways.

For starters it can be a catalyst for parents to start engaging in conversations with their children about using drugs just as there have been conversations about drinking. Secondly, it could also lower the stigma which may help those that have a problem with substances which in turn could decrease the shame that one experiences with admitting they have a problem. Pamphlets are given to students which go over the signs and symptoms of being an alcoholic. Granted some our outdated but it gives the student an awareness of troubling behavior. By providing handouts on the criteria of abusing or being dependent on drugs could also bring such awareness.

The one thing that I continue to hear at the treatment center I work for is that the client consistently feels they are alone in their use. That no one will get the feelings and actions that they have had either prior to or as a result of their use. If a dialogue can be established about the prevalence of drugs within the school system it can show others that there are people out there that experience what these students experience. Students have the view that they can admit that they drink because a lot of others drink yet if they admit they think they have a problem with drugs they become criminal. Isn't it illegal to be under the influence of alcohol prior to being legal age? So why is there this perception that it is ok to talk about underage drinking versus using drugs when both are illegal? I feel that if we talk about one we should feel comfortable enough to talk about the other.

I understand that this will be a long time coming. Schools did not mention drunk driving to students overnight. It took accidents and deaths for people to consider talking about it. But if we begin to take these small steps towards acknowledging drug usage we may be able to help students prior to becoming clients we see in the future whose lives are in shambles as a result of their drug use. Do we want to continue to acknowledge one without considering the other?

*Corresponding author: Nicholas Johnson, Intensive Outpatient Director, New Dawn Treatment Centers in Sacramento, 1304 East St Suite 208, Redding, California 96001, USA, Tel: 916-723-1319/(530) 419-5582; E-mail: njohnson@ newdawnts.com

Received September 30, 2015; Accepted January 23, 2016; Published January 29, 2016

Citation: Johnson N (2016) Will Schools Ever Open Up on the Growing Substance Problem?. J Psychiatry 19: 349 doi:10.4172/2378-5756.1000349

Copyright: (c) 2016 Johnson N. This is an open-access article distributed under the terms of the Creative Commons Attribution License, which permits unrestricted use, distribution, and reproduction in any medium, provided the original author and source are credited 